Farum

Sociológico

\section{Forum Sociológico}

Série II

37 | 2020

Número 37

\title{
Ensino superior a distância e o desenvolvimento de competências profissionais : Uma análise com base nas perceções dos diplomados
}

Distance Learning and professional competences development : analysis based on graduates' perception

Susana Henriques, Cláudia Neves, Ana Paula Silva, Pedro Abrantes, Bárbara Bäckström, Isabel Falé, Marc Jacquinet, Olga Magano e Maria do Rosário Ramos

\section{OpenEdition}

Journals

Edição electrónica

URL: https://journals.openedition.org/sociologico/9511

DOI: 10.4000/sociologico.9511

ISSN: 2182-7427

Editora

CICS.NOVA - Centro Interdisciplinar de Ciências Sociais da Universidade Nova de Lisboa

Edição impressa

Paginação: 49-62

ISSN: 0872-8380

\section{Refêrencia eletrónica}

Susana Henriques, Cláudia Neves, Ana Paula Silva, Pedro Abrantes, Bárbara Bäckström, Isabel Falé Marc Jacquinet, Olga Magano e Maria do Rosário Ramos, «Ensino superior a distância e o desenvolvimento de competências profissionais : Uma análise com base nas perceções dos diplomados», Forum Sociológico [Online], 37 | 2020, posto online no dia 23 dezembro 2020, consultado o 31 março 2022. URL: http://journals.openedition.org/sociologico/9511 ; DOI: https://doi.org/ 10.4000/sociologico.9511 


\title{
ENSINO SUPERIOR A DISTÂNCIA E O DESENVOLVIMENTO DE COMPETÊNCIAS PROFISSIONAIS: UMA ANÁLISE COM BASE NAS PERCEÇÕES DOS DIPLOMADOS
}

\section{DISTANCE LEARNING AND PROFESSIONAL COMPETENCES DEVELOPMENT: ANALYSIS BASED ON GRADUATES' PERCEPTION}

\author{
Susana Henriques \\ Centro de Investigação e Estudos de Sociologia (CIES-Iscte), Iscte - Instituto Universitário de Lisboa \& Universidade \\ Aberta (UAb), Portugal
}

Cláudia Neves

Laboratório de Educação e Ensino a Distância (LE@D), Universidade Aberta (UAb), Portugal

Ana Paula Silva

Universidade Aberta (UAb), Portugal

Pedro Abrantes

Centro de Investigação e Estudos de Sociologia (CIES-Iscte), Iscte - Instituto Universitário de Lisboa \& Universidade Aberta (UAb), Portugal

\section{Bárbara Bäckström}

- Universidade Aberta (UAb); CICS.NOVA \& Centro de Estudos das Migrações e Relações Interculturais (CEMRI), Portugal Isabel Falé

Centro de Linguística da Universidade de Lisboa (CLUL), Universidade Aberta, Portugal

Marc Jacquinet

Universidade Aberta (UAb) \& Centro de Investigação sobre o Espaço e as Organizações (CIEO), Universidade do Algarve, Portugal

\section{Olga Magano}

Centro de Investigação e Estudos de Sociologia (CIES-Iscte), Iscte - Instituto Universitário de Lisboa \& Universidade Aberta (UAb), Portugal

\section{Maria do Rosário Ramos}

Universidade Aberta (UAb) \& Centro de Matemática, Aplicações Fundamentais e Investigação Operacional (CMAFcIO, UL), Portugal

\footnotetext{
Resumo

Quem são os estudantes que optam pela Educação Superior a Distância? Quais as suas expetativas e grau de satisfação com os cursos nesta modalidade? Qual o impacto do curso na vida profissional e pessoal do estudante da UAb? O presente artigo centra-se nestas questões, seguindo um enquadramento teórico que mobiliza estudos sobre a procura de respostas para novos públicos e novas necessidades nas sociedades atuais. O desenho metodológico seguiu a aplicação de um questionário, desenhado no âmbito do Observatório dos Percursos Profissionais e de Vida dos Diplomados da Universidade Aberta, aos estudantes que terminaram a licenciatura em 2014 e 2015. Os resultados remetem para uma satisfação global com a realização da licenciatura online, na medida em que revelam conforto no uso da plataforma e reconhecem vantagens no regime de aprendizagem. Destaca-se a valorização do prestígio social associado ao diploma de ensino superior. Concluímos que a pesquisa sobre o fenómeno da empregabilidade no ensino superior precisa de mais desenvolvimento. Os estudantes adultos apresentam um conjunto de necessidades diferenciadas, sobretudo relacionadas com a aquisição de competências para melhorar as suas condições profissionais, de empregabilidade e o desenvolvimento das suas carreiras. Os dados deste estudo
} 
reforçam a ideia de educação ao longo da vida associada ao ensino a distância como importante forma de desenvolvimento e aquisição não só de conhecimentos, como também de competências transversais fundamentais a todos os contextos da vida e para a mobilidade profissional.

Palavras-chave: empregabilidade, graduados do ensino superior, perfis e competências

\begin{abstract}
Who are the students who choose Distance Higher Education? What are their expectations and satisfaction with the online courses? What are the impacts of the course on UAb student professional and personal life? The present article focuses on these questions following a theoretical framework that mobilizes studies searching for answers to new audiences and new needs in current societies. The methodological design followed the application of a survey, designed within the scope of the Observatório dos Percursos Profissionais e de Vida dos Diplomados da Universidade Aberta, to the students who finished their degree in 2014 and 2015. The results refer to a global satisfaction with the accomplishment of the degree online, insofar as they reveal comfort in using the platform and recognize advantages in e-learning. The social prestige associated with the higher education diploma stands out. We conclude that research on the phenomenon of employability in higher education needs further development. Adult students have a set of differentiated needs, mostly related more to the acquisition of skills to improve their professional conditions, employability and the development of their careers. Data in this study reinforce the idea of lifelong education associated with distance learning as an important way of developing and acquiring not only knowledge, but also transversal competences that are fundamental to all contexts of life and for professional mobility.
\end{abstract}

Keywords: employability, higher education graduates, profiles and skills

\section{Introdução}

Quem são os estudantes que optam pela Educação Superior a Distância (EaD), quais as suas expetativas com os cursos nesta modalidade e quais os impactos deste tipo de formações nas suas vidas são questões que não têm sido centrais na investigação neste campo. O presente artigo encontra-se organizado em torno destas questões, tomando como referente empírico a Universidade Aberta (UAb), por ser a única universidade pública portuguesa de educação a distância. Esta instituição de ensino superior tem a particularidade de ter uma população estudantil que se distingue das restantes universidades públicas portuguesas. São estudantes adultos, empregados, que veem na educação a distância uma oportunidade de conciliar a vontade de progredir nos estudos com a vida familiar e profissional, devido ao modelo pedagógico flexível, centrado no estudante e a distância que orienta a oferta pedagógica desta universidade (Abrantes, Bäckström, Falé, Henriques, Jacquinet, Magano, Neves, Ramos \& Silva, 2018; Abrantes, Bäckström, Neves, Jacquinet, Magano \& Henriques, 2016b).

Voltar ao sistema educativo em busca de qualificações na idade adulta pode tornar-se um desafio. Esta necessidade de adquirir mais competências e conhecimentos, tendo em vista a progressão profissional, a satisfação pessoal e a procura de melhores condições económicas, tem feito aumentar a procura de formação no Ensino Superior nas últimas décadas (Pereira, 2007).

No âmbito do Observatório dos Percursos Profissionais e de Vida dos Diplomados da Universidade Aberta foi construído e aplicado um questionário com vista a caracterizar os percursos profissionais e de vida dos licenciados, com base no qual foram recolhidos dados. Neste artigo apresentamos os dados que se referem aos diplomados do $1 .{ }^{\circ}$ ciclo da Universidade Aberta que concluíram a sua licenciatura entre 2014 e 2015, procurando enfatizar: Qual o impacto do curso na vida profissional e pessoal do estudante da UAb? Ao procurar responder a esta questão, visamos contribuir para discussões teóricas emergentes em torno dos impactos sociais do ensino superior em geral e do ensino superior a distância em particular nos diplomados. Referimo-nos ao papel que a educação a distância pode desempenhar no contexto da aprendizagem ao longo da vida, designadamente no desenvolvimento de competências no âmbito da empregabilidade.

Os temas da empregabilidade e da inserção no mercado de trabalho têm sido alvo de preocupações constantes por parte dos decisores políticos, acompanhados por amplas discussões académicas que impulsionaram a massificação de vários conceitos muitas vezes confundidos e normalmente mais associados às camadas mais jovens e ao seu processo de passagem do sistema de educação/formação para a vida ativa. Embora não seja objetivo deste artigo contribuir para a estabilização destes conceitos, 
salientamos que o trabalho empírico que suporta este estudo tem como principal foco analisar os impactos sociais e profissionais da Educação a Distância em adultos. Nesse sentido, iremos recorrer ao termo "empregabilidade" preconizado por autores como Charlot e Glasman (1998), Cadin, Guerin e Pigeyre (1997), Brown, Hesketh e Williams (2002), mais associado à ideia de um processo de construção ao longo do tempo que mobiliza aprendizagens e competências que podem originar mudanças na situação de emprego atual ou para outro emprego ou categoria profissional. Na linha de McQuaid e Lindsay (2004), não defendemos a empregabilidade como um esforço individual, mas sim como um processo potenciado não apenas pelos indivíduos, mas também pelas empresas.

Embora seja este o foco do presente artigo, importa referir que o estudo inclui também uma análise objetiva de indicadores de empregabilidade e de mobilidade social e profissional com especial enfoque nos resultados sobre perceções e competências, uma vez que estes permitem uma análise mais aprofundada sobre o modelo de ensino a distância e a sua relação com as dinâmicas económicas, sociais e culturais, nomeadamente, as que têm um impacto direto no mercado de trabalho (Abrantes et al., 2018; Abrantes, Henriques, Bäckström, Jacquinet, Magano \& Neves, 2016a; Abrantes et al., 2016b; Abrantes, Henriques, Bäckström, Jacquinet, Magano, Neves, 2016c; Magano, Abrantes, Bäckström, Neves, Jacquinet \& Henriques, 2016; Magano, Abrantes, Ramos, Bäckström, Neves, Henriques, Jacquinet, Falé \& Silva, 2018; Neves, Henriques, Abrantes, Bäckström, Jacquinet \& Magano, 2017).

\section{A procura de respostas para novos públicos e novas necessidades societais}

Nos finais da década de 1980 e inícios da de 1990, ainda antes da implementação do Processo de Bolonha na Europa, o Reino Unido já tinha conceptualizado uma nova missão para o ensino superior com o propósito de contribuir para a formação e para o emprego, através da transferência do conhecimento inovador das universidades, para promover o desenvolvimento económico e social das nações (Deem, 1998). Por outro lado, assumia-se cada vez mais que o conhecimento teórico e técnico adquirido pelo graduado era insuficiente para vingar no mundo do trabalho. Portanto, era necessário desenvolver, a par, atributos extracurriculares que o capacitassem para desempenhos laborais mais eficazes (Deem, 1998).

Preconizava Harvey (2005) que o ensino superior deveria estabelecer ligações com os empregadores, para que fossem implementadas estratégias concertadas que erradicassem a carência de qualificações, sobretudo em áreas mais sofisticadas, para responder aos desafios da sociedade. Os programas dos cursos lecionados nas universidades, em consonância, deveriam não só refletir a área temática do curso, mas também as necessidades do mercado de trabalho (Silva, Lourtie \& Aires, 2013, p. 108).

As organizações necessitam de graduados com diversos perfis em termos de qualificação e de competências (Harvey, 2005; Silva, 2010). Harvey (2005) identificou três tipos de perfis de graduados necessários nas empresas: Adaptative, Adaptable e Transformative. O perfil adapative corresponde a um desempenho do trabalhador que corre pequenos riscos, evita questionar os procedimentos da empresa e se adapta à cultura da organização. O perfil adaptable corresponde ao desempenho do indivíduo que tem vontade e capacidade de aprender, de integrar novos conhecimentos e novas competências às que já possui, demonstrando iniciativa, confiança em usar todo o seu potencial em prol da mudança e da melhoria da organização. Este perfil é ainda capaz de motivar equipas, o que envolve ter uma capacidade elevada de comunicação a diversos níveis. Por último, o perfil transformative corresponde a um desempenho sofisticado, ou seja, ao de ser capaz de usar competências elevadas, tais como a capacidade de análise, de crítica e de síntese. Este perfil reflete também a apetência para liderar pessoas, obtendo o melhor das mesmas, maximizando o seu potencial e as suas ideias.

As organizações contam com colaboradores que sejam capazes de gerir a mudança e que adicionem valor à organização, ou seja, que possuam o "potencial transformador" para o "reforço contínuo" da organização e sua consequente evolução" (Silva, 2010, pp. 55-57). Porém, encontrar ou identificar um graduado com as características do último perfil - transformative - não é uma tarefa linear. Quer isto dizer que, em última análise, mesmo que os graduados detenham potencial transformador, não é garantido que sejam capazes de proporcionar uma evolução na organização, uma vez que o diplomado intelectualmente brilhante pode não proporcionar o reforço contínuo na organização, ou seja, intelecto e conhecimento não são indicadores diretos de potencial transformador. É ainda relevante salientar que são necessários os três tipos de perfis nas organizações, por um lado, porque nem todas as áreas de uma organização necessitam do perfil mais sofisticado e as diversas organizações apresentam necessidades diferentes; por outro lado, porque diferentes situações e momentos requerem um perfil e desempenho diferenciado, também (Silva, 2010, p. 56).

Reich designou por Symbolic Analytics os indivíduos que são reconhecidos como imaginativos e criativos, que demonstram elevada compreensão dos conteúdos disciplinares e das competências genéricas, as quais, conjugadas, se constituem 
como uma ótima base para produzir excelentes desempenhos (como citado em Silva, Lourtie \& Aires, 2013, p. 108). Para Silva (2010, p. 57), tal significa que o desenho dos programas curriculares para os estudantes deve estar focado em quatro áreas: 1) abstração (teoria e/ou dados empíricos relativos à teoria e/ou utilização de fórmulas, equações, modelos e metáforas); 2) sistema de pensamento (inserir/ver a parte no contexto mais amplo); 3) experimentação (intuitivamente ou analiticamente); 4) colaboração (o que envolve a comunicação e competências de trabalho em equipa).

Desde os anos 80 que organizações internacionais como a UNESCO, o Banco Mundial, a União Europeia e a OCDE se têm vindo a preocupar com o aumento de qualificações e competências fundamentais para os cidadãos do século XXI. A partir do século $X X$, estas preocupações tornaram-se mais evidentes, e um pouco por todo o mundo foram publicados relatórios e reflexões sobre as competências essenciais que deverão alavancar o desenvolvimento do século XXI. Neste contexto, tendo em vista a definição de um referencial de competências, a OCDE divulgou o documento The Definition and Selection of Key Competencies (OCDE, 2005). Neste documento são definidas competências que estão integradas em três grandes grupos: utilização interativa de ferramentas (como a linguagem ou a tecnologia); interação entre grupos heterogéneos; e agir responsavelmente e de forma autónoma. Estas categorias, cada uma com um foco específico, são interrelacionadas e formam coletivamente uma base para identificar e mapear competências-chave. Num documento mais recente da OCDE (2018) defende-se que a preparação dos estudantes para o futuro requer que estes exerçam agência, na sua própria educação e ao longo da vida. $A$ agência implica um sentido de responsabilidade para participar no mundo e, deste modo, influenciar para melhor pessoas, eventos e circunstâncias. A agência requer, pois, a capacidade para definir um propósito orientador e identificar as ações necessárias para atingir tal objetivo (OCDE, 2018, p. 4).

Neste cenário, as Instituições de Ensino Superior (IES) devem ter em atenção estes aspetos no desenho estratégico da sua oferta formativa para prepararem os seus estudantes para a empregabilidade. Concretamente no caso da educação a distância, estas questões colocam-se de igual modo, se não com maior incidência, na medida em que a ausência de barreiras de espaço e de tempo permite a criação de escala e o acesso aos cursos por parte de estudantes situados em zonas geograficamente dispersas e contextualmente diversificadas (Pereira, 2007). No caso dos diplomados da UAb, estão distribuídos pelo território nacional e ilhas, mas também por outros países da Europa, América e África (Abrantes et al., 2018).

\section{Cenários e tendências do Ensino Superior: Empregabilidade no Ensino Superior online}

Existem diversos estudos sobre modelos de ensino que versam sobre a empregabilidade, um dos quais, o modelo USEM (Understanding, Skills, Efficacy, Employability, Metacognition), de Knight e Yorke (2003), tem sido testado no ensino superior. Um exemplo da sua aplicação foi o projeto Skills Plus. Os autores partiram de uma tabela de competências com o objetivo de encontrar referenciais comuns, com base no diálogo entre estudantes e docentes.

O modelo USEM enfatiza a centralidade do sujeito na escolha de seu próprio percurso, aplicando as suas ferramentas, e propõe que a empregabi-

Figura $1 \triangleright$ Modelo USEM

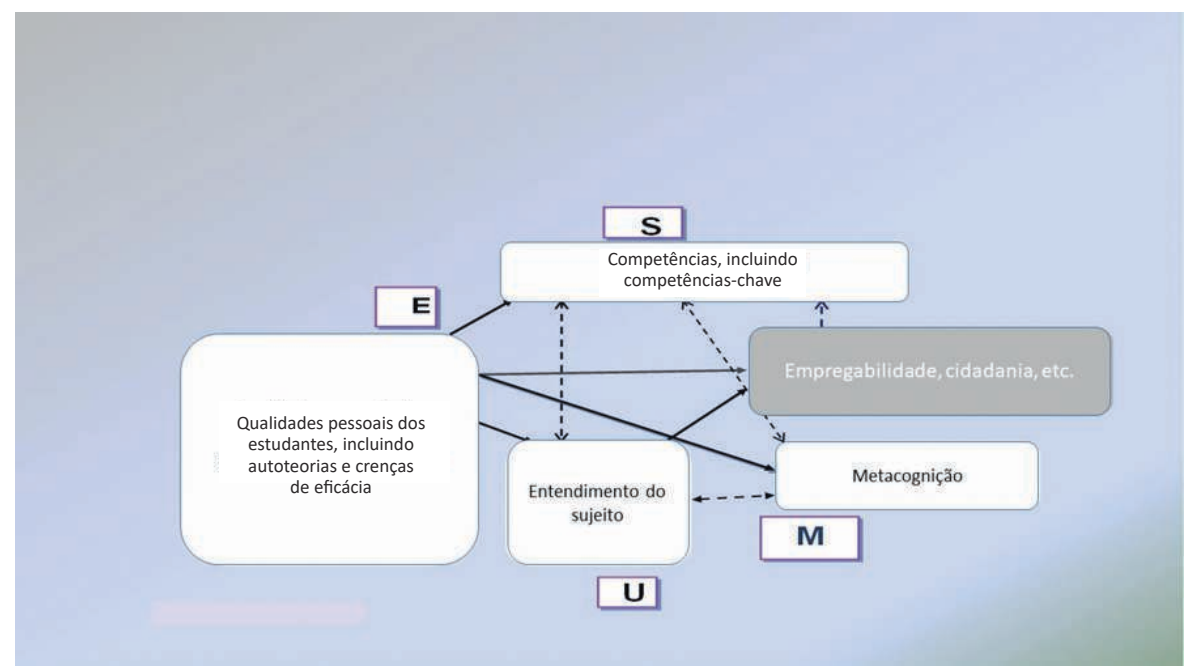

Fonte: Adaptado de Knight \& Yorke (2003) 
lidade é influenciada: 1) pela compreensão que o estudante tem da área disciplinar ou campo profissional e das competências genéricas adquiridas; 2) pelo conjunto de crenças de eficácia, de autoteorias e de qualidades pessoais do estudante, com base nas quais se sente capaz de fazer a diferença; 3) e pela metacognição, ou seja, a tomada de consciência daquilo que aprende, da reflexão que faz sobre, na, e para a ação, uma aprendizagem contínua que Ihe permite desenvolver as capacidades adquiridas (Zulauf, 2006, p. 135).

Existem outros modelos posteriores que exploraram a relação entre o ensino-aprendizagem e a empregabilidade. Conforme refere Boffo (2019, p. 14), o modelo conhecido por DOTS, desenvolvido por Anthony Watts em 2006, apesar de estar mais focado para a compreensão de como são construídas as carreiras profissionais, apresenta quatro parâmetros: 1) aprendizagem de decisão, o que envolve ser capaz de planear e direcionar o conhecimento adquirido; 2) perceção da oportunidade; 3) aprendizagem da transição, ou seja, ser capaz de transferir e direcionar oportunidades; 4) autoconsciência de ser capaz de expressar e reconhecer motivações (habilidades e responsabilidades que podem apoiar a carreira). Outro modelo posterior é o de Pool e Sewell (2007), o qual pretende colmatar as lacunas dos modelos anteriores. Este modelo apresenta cinco elementos, introduzindo a inteligência emocional enquanto capacidade de manter o equilíbrio e de se ligar com os outros nas relações profissionais.

Boffo (2019) refere ainda o modelo CareerEDGE, que, além de resumir os modelos anteriores, amplia-os e desenvolve-os. Este modelo baseia-se nos seguintes elementos: (1) aprendizagem de desenvolvimento de carreira; (2) experiência, dando-se importância às experiências adquiridas no local de trabalho e nos contextos informais de vida quotidiana; (3) nível de conhecimento, entendimento e habilidades dos sujeitos (tal como no modelo USEM, reconhece-se os conhecimentos e as habilidades como a base essencial de referência); (4) habilidades genéricas/transversais; (5) inteligência emocional - este ponto introduz um elemento crucial para motivação e consciência de si e dos outros, desenvolvimento pessoal e trabalho em equipa (Boffo, 2019, p. 15). Outros autores têm vindo a reforçar a ligação entre a empregabilidade e os resultados da aprendizagem em cursos de nível superior, em programas de graduação e de formação pós-graduada (como por exemplo, Finch, Hamilton, Riley \& Zehner, 2013).

$\mathrm{Na}$ generalidade destes modelos determina-se uma relação clara, convincente e inconfundível entre aprendizagem e empregabilidade (Boffo, 2019, p. 16). A questão que se coloca aqui é a de que a preparação do estudante não se deve focar única e exclusivamente no perfil profissional, até porque dificilmente o curso estará diretamente ligado a uma só profissão.

Conforme Zulauf (citado em Silva, 2010), as instituições de ensino superior podem melhorar a empregabilidade dos seus estudantes ao desenvolver as metacognições, ou seja, contribuindo para que o estudante aprenda a aprender, promovendo a autonomia e a confiança em si próprio. O estudante, por regra, não está ciente de que as teorias que adota influenciam as suas escolhas intelectuais e se refletem nos desempenhos das tarefas que realiza. No âmbito da aprendizagem ao longo da vida é fundamental que o indivíduo possa explorar e rentabilizar toda a aprendizagem adquirida (formal, não-formal e informal), fazendo uma melhor conexão entre as suas expectativas e a realidade laboral, garantido não só o seu crescimento e desenvolvimento, mas também a sua inserção social. Para tal, é necessário que a empregabilidade seja inserida nos curricula, nas estratégias de aprendizagem, e que existam avaliações sobre a sua aplicação (Silva, 2010, p. 74).

Yorke definiu empregabilidade como

a set of achievements - skills, understandings and personal attributes - that make graduates more likely to gain employment and be successful in their chosen occupations, which benefits themselves, the workforce, the community and the economy (2006, p. 8).

No mesmo sentido, Lourtie defende que a empregabilidade deve ser um objetivo de qualquer formação, de qualquer tipo (citado em Silva, 2010, p. 62).

Porém, a empregabilidade do diplomado depende de vários fatores, tornando-se difícil delimitar a interferência de cada um desses fatores no resultado final que é o emprego obtido. Knight (citado em Silva, 2010, p. 61) salienta os seguintes aspetos: 1) a empregabilidade é probabilística, porque está relacionada com a incerteza dos fatores externos: variáveis socioeconómicas, tais como o estado da economia global, mas também nacional, regional ou local; 2) obter emprego e ter sucesso no trabalho são situações distintas, e alguns aspetos específicos do mundo do trabalho podem não ser abordados no ensino superior; 3) o primeiro emprego, para muitos diplomados, não traduz a ocupação que desejariam e que estimularia o desenvolvimento das suas competências. Em situações de escassez de emprego, os diplomados obtêm o emprego possível, em face das circunstâncias.

O estudo sobre os diplomados da Universidade Aberta, com a especificidade que advém do facto de terem sido estudantes em EaD, exige que se convoquem modelos que versam sobre a empregabilidade. Frequentemente, não é uma empregabilidade projetada no futuro, mas uma empregabilidade 
vivida no presente. Deste modo, no nosso estudo a empregabilidade ao nível teórico corresponde ao potencial que o estudante possui para adaptar e flexibilizar os seus conhecimentos, competências e atitudes ao mercado de trabalho, promovendo a sua inclusão social e garantindo qualidade à sua vida. Ao nível prático, a empregabilidade é o potencial operacionalizado através da aplicação de competências no mundo do trabalho.

\section{Metodologia}

Assumimos aqui que as perceções que os estudantes têm sobre as competências para a empregabilidade estão intrinsecamente associadas aos seus contextos sociais e às suas especificidades. Os estudantes da Universidade Aberta contam ainda com a particularidade da mediação tecnológica nos processos de ensino e aprendizagem, enquadrados pelo Modelo Pedagógico Virtual ${ }^{\circledR}$ da UAb.

A Universidade Aberta, desde a sua fundação em 1988, é pioneira na Educação Superior a Distância em Portugal, sendo a única universidade pública portuguesa a lecionar todos os cursos em regime e-learning. A UAb tem uma ampla oferta educativa,

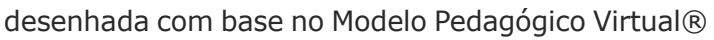
(MPV), especificamente concebido para esta universidade e que privilegia os seguintes postulados: aprendizagem centrada no estudante; flexibilidade pela ausência de barreiras espaciotemporais; interação diversificada (entre estudantes, estudantes e docentes, entre estudantes e recursos); e inclusão digital enquanto competência essencial de cidadania nas sociedades atuais (Mendes, Bastos, Amante, Aires \& Cardoso, 2018; Pereira, Mendes, Morgado, Amante \& Bidarra, 2007). Estes princípios orientam a organização do ensino, o papel do estudante e o do professor, a planificação, conceção e gestão das atividades de ensino e aprendizagem, o tipo de materiais e recursos pedagógicos e a avaliação das competências adquiridas.

No centro do MPV ${ }^{\circledR}$ da UAb está o estudante enquanto indivíduo ativo, construtor do seu próprio conhecimento e integrado numa comunidade de aprendizagem (Aires, Azevedo, Gaspar \& Teixeira, 2007). O processo de ensino e aprendizagem, através de situações pedagógicas diversificadas, deverá facilitar a aquisição e o desenvolvimento de competências transversais, exigidas pela sociedade digital, bem como a aquisição de competências específicas na área de saber do curso frequentado pelo estudante. O planeamento das atividades de ensino e aprendizagem assume-se como uma tarefa rigorosa, voltado para o desenvolvimento de competências prioritárias em cada unidade curricular (Pereira et al., 2007). E o resultado da aprendizagem do estudante surge da conjugação desta componente planificada com aprendizagens autónomas e colaborativas. As aprendizagens colaborativas revelam-se particularmente importantes, na medida em que preparam os estudantes para as necessidades das organizações, cujas tarefas assentam fundamentalmente no trabalho desenvolvido em equipas multidisciplinares e na construção conjunta de conhecimento (Pereira et al., 2007).

Neste contexto, os princípios enumerados do MVP ${ }^{\circledR}$ da UAb vão ao encontro dos desafios atualmente lançados ao Ensino Superior, no domínio da empregabilidade. Os primados da flexibilidade, autonomia, reflexividade e sentido crítico orientam-se para o desenvolvimento das metacognições dos estudantes, das suas perceções de auto-eficácia e do conhecimento sobre os seus mecanismos de ação, pensamento e desenvolvimento, dimensões estreitamente vinculadas ao desenvolvimento de competências para a empregabilidade.

O Modelo Pedagógico Virtual ${ }^{\circledR}$ da Universidade Aberta traduz, assim, uma abordagem especializada combinando princípios da pedagogia e tecnologia da Educação a Distância e do e-learning. A par, reflete ainda a vasta experiência adquirida nas redes virtuais e nas redes da globalização do conhecimento. É um modelo exclusivo da UAb, assumido como estratégico e dinâmico, na medida em que incorpora as melhorias que decorram não só da investigação ao nível da conceptualização e da evolução tecnológica em EaD, como também da investigação sobre a perceção dos estudantes e diplomados. Neste contexto, os objetivos centrais deste artigo consistem em conhecer as competências para a empregabilidade mais valorizadas pelos estudantes da UAb e em explorar as suas perceções sobre as competências necessárias para a empregabilidade. Importa lembrar que foi nossa intenção conhecer de modo aprofundado esta problemática numa universidade pública que disponibiliza toda a sua oferta pedagógica em regime de e-learning, dada a especificidade que representa.

Considerámos neste estudo todos os licenciados da UAb que concluíram os respetivos cursos entre 2014 e 2015. Para tal, elaborámos um inquérito por questionário, aplicado online, a estudantes que tivessem concluído a licenciatura há, pelo menos, dois ou três anos. O questionário agora aplicado é um refinamento do questionário aplicado aos diplomados de 2012-2013, o primeiro estudo, um processo que envolveu a pré-testagem e análise de validade e fiabilidade. A estrutura do inquérito por questionário é composta por cinco blocos ou dimensões: (1) perfil sociográfico; (2) percurso académico; (3) balanço de competências; (4) impacto da licenciatura; (5) projetos de futuro (Abrantes et al., 2018; Abrantes et al., 2016b). Importa, pois, sublinhar que, embora o estudo tenha incluído a análise de indicadores objetivos de empregabilidade e de mobilidade social e profissional, centramo-nos 
aqui nos resultados que dão conta das competências profissionais a partir das perceções dos diplomados.

A aplicação do questionário iniciou-se com o envio de um convite via correio eletrónico a todos os licenciados de 2014 e 2015 solicitando o seu preenchimento. Durante todo o processo de recolha de informação foi feito o acompanhamento por via eletrónica e telefónica para apoio ao estudante e esclarecimento de dúvidas.

O universo é de 1079 diplomados, tendo o número de respostas válidas sido de 420 , obtendo-se uma taxa de resposta de $39 \%$. Esta taxa tem subjacentes respostas representativas dos diplomados de todos os cursos e implica uma margem de erro total de cerca de $3,7 \%$.

\section{Competências dos diplomados da UAb}

Como referimos antes, o estudo abrangeu diversas dimensões, desde o percurso académico aos projetos de futuro. Neste artigo focamo-nos no balanço de competências e no impacto da licenciatura. O balanço das competências do questionário avaliou a satisfação dos estudantes com os cursos frequentados na Universidade Aberta. Desta forma, a satisfação traduz-se no barómetro que mede a qualidade do processo de ensino e aprendizagem. 0 impacto da licenciatura traduz as implicações, diretas ou indiretas, da licenciatura na vida profissional e pessoal dos estudantes.

Neste estudo, definimos os seguintes objetivos para a análise das competências e das relações que os estudantes afirmam ter desenvolvido na licenciatura: "identificar o grau de satisfação dos estudantes com a frequência dos cursos; identificar a perceção que os diplomados têm sobre o ensino online; identificar os principais objetivos adquiridos ao longo dos cursos; identificar se os diplomados consideram que a frequência dos cursos serviu como preparação para a vida profissional e em que medida; identificar os contributos dos cursos para o desenvolvimento pessoal, profissional e social dos diplomados; identificar perceções sobre a imagem pública da UAb; identificar principais características associadas aos estudantes da UAb" (Abrantes et al., 2018, p. 21). Nas páginas que se seguem, expomos os resultados da análise para cada um destes aspetos.

\section{Grau de satisfação com a frequência dos cursos}

Relativamente à frequência do curso na UAb, verifica-se um grau de satisfação bastante elevado, agrupando o grau de "muito satisfeito" e "satisfeito" os valores situam-se entre um mínimo de $77,1 \%$ e um máximo de $97,1 \%$, nas diversas dimensões, como ilustra o Gráfico 1 . Do total de 420 respondentes ao inquérito, as maiores percentagens de respostas de inquiridos a manifestarem-se "muito satisfeitos" e "satisfeitos" incidem sobre as aprendizagens realizadas $(97,1 \%)$, os planos de estudos e conteúdos abordados $(95,7 \%)$ e os exames $(88,9 \%)$. Relativamente ao nível "muito satisfeitos", destacamos as percentagens apuradas nas aprendizagens (49\%), nos planos de estudo e conteúdos $(37,1 \%)$ e com os colegas $(34,3 \%)$. No que se refere às respostas "pouco satisfeitos" e "nada satisfeitos", as percentagens mais elevadas dizem respeito aos docentes, aos serviços administrativos e à interação com os colegas $(21, \%, 14 \%$ e $10 \%$, respetivamente).

Gráfico $1 \triangleright$ Grau de satisfação relativamente à frequência do curso

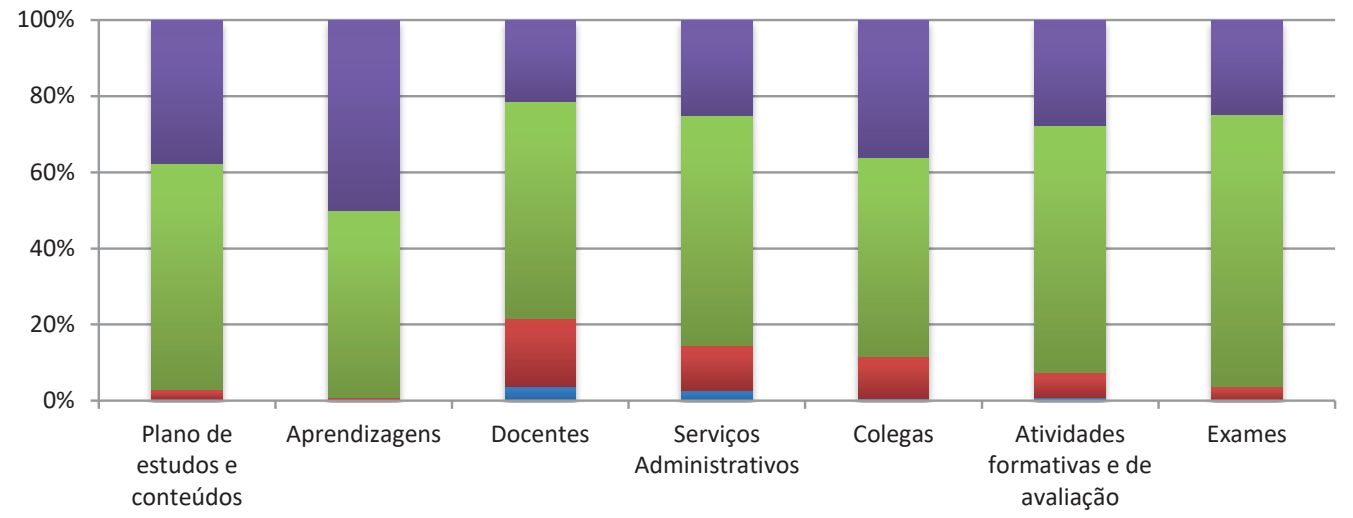

Muito Satisfeito $\quad$ Satisfeito $\quad$ Pouco Satisfeito $\quad$ Nada Satisfeito

Fonte: Elaboração própria (Abrantes et al., 2018, p. 21) 


\section{Perceção dos diplomados sobre a educação} online

Sabemos que o MPV ${ }^{\circledR}$ da Universidade Aberta (descrito no ponto 2) é dinâmico, na medida em que vai incorporando as melhorias que decorram do campo científico da EaD, assim como os resultados de investigações aplicadas ao contexto UAb - caso dos inquéritos regulares a estudantes e diplomados. Neste sentido, procurámos inquirir os diplomados sobre a satisfação com o ensino online como meio de aprendizagem, sobre o conforto com o uso da plataforma, o sentimento de pertença a uma comunidade, o à-vontade com a interação com colegas e professores, bem como sobre a interação e amizade com colegas e docentes.

As respostas indicam uma satisfação geral muito elevada em todas as dimensões selecionadas, se se agrupar o nível "concordo totalmente" e "concordo parcialmente" o ensino online como excelente meio de aprendizagem e o conforto no uso da plataforma de ensino a distância, atingem os valores mais elevados, respetivamente de $98,1 \%$ e $96,9 \%$. As restantes dimensões, com valores ligeiramente mais baixos, não deixam de evidenciar uma satisfação muito elevada, por ordem decrescente, à-vontade na interação com os colegas $(90,2 \%)$, sentimento de pertença a uma comunidade $(86,9 \%)$ e desenvolvimento de amizades com colegas e professores $(81,7 \%)$.

\section{Principais objetivos adquiridos ao longo do curso}

Outra questão que está relacionada com a frequência do curso e com a perceção do ensino online são os principais objetivos que os diplomados consideraram ter alcançado durante a frequência dos cursos da UAb. Os indicadores aqui considerados pretendem responder às questões de empregabilidade e mobilidade social e profissional.

Nesta resposta a grande maioria dos estudantes destacou o facto de o curso ter permitido ampliar a sua autonomia, cultura geral e sentido crítico $(88,1 \%)$. Destacam-se, ainda, a possibilidade de desenvolver capacidades de análise e síntese $(87,1 \%)$, uma das principais características do ensino online, seguida de dominar os fundamentos do campo ou área $(79,3 \%)$ e de desenvolver capacidades de comunicação $(74,3 \%)$.

Esta escolha dos estudantes permite concluir que, embora valorizem bastante a aquisição de conhecimentos e conteúdos específicos nas áreas em que se diplomaram, não deixam de realçar, em primeiro lugar, a importância das competências transversais tais como a autonomia, o sentido crítico e a capacidade de análise e síntese. A capacidade de trabalhar em grupo foi o objetivo menos indicado pelos diplomados, apesar de ter atingido um valor bastante expressivo de $50,3 \%$.

As respostas corroboram os estudos atrás referidos de Knight e York (2003), aproximando o modelo USEM e o Modelo Pedagógico Virtual da Universidade Aberta. $O$ estudante da UAb, predominante adulto e já integrado no mercado de trabalho, assume a centralidade na sua empregabilidade, acreditando em si mesmo e em que é capaz de conjugar conhecimentos e competências individuais, examinando esses atributos com metacognição, sendo capaz de responder às situações de trabalho com meta-reflexividade (Magano et al., 2018).

Gráfico $2 \triangleright$ Perceções sobre o ensino online na Universidade Aberta

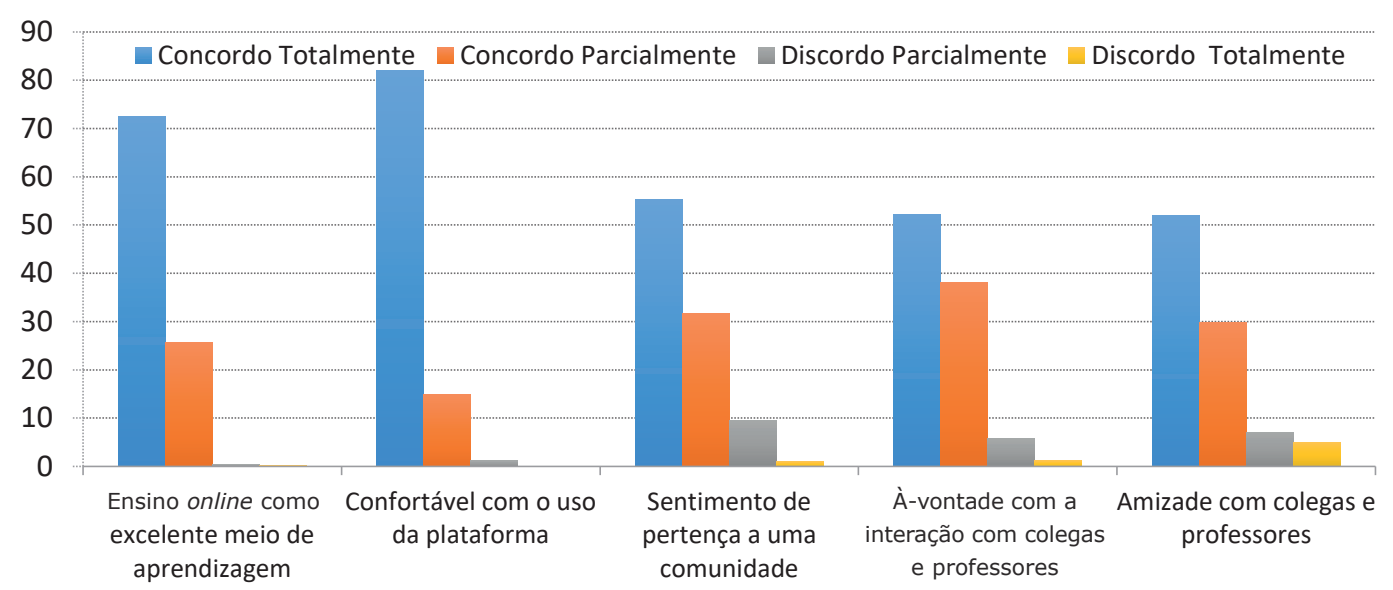

Fonte: Elaboração própria (Abrantes et al., 2018, p. 22) 
Gráfico $3 \triangleright$ Objetivos adquiridos ao longo do curso

Desenvolver capacidades de trabalho em grupo

Aprofundar competências no uso das tecnologias

Desenvolver capacidades de comunicação

Ampliar autonomia, cultura geral e sentido crítico

Desenvolver capacidades de análise e síntese

Dominar fundamentos do campo ou área

Em parte/Não concordo

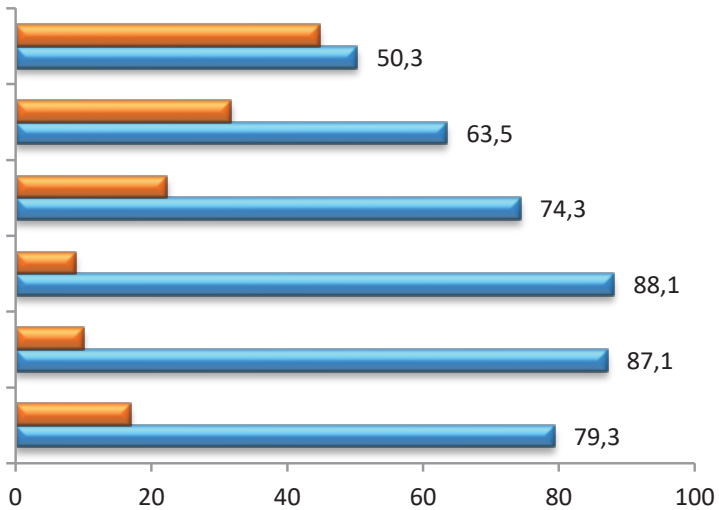

Concordo totalmente/em grande parte

Fonte: Elaboração própria (Abrantes et al., 2018, p. 23)

\section{Contributo dos cursos para a vida profissional}

Na preparação para a vida profissional, os estudantes privilegiam o desenvolvimento da capacidade crítica, de planeamento e inovação no trabalho $(75,4 \%)$, bem como o desenvolvimento de capacidades de interação e resolução de problemas $(70,2 \%)$. Os itens menos valorizados pelos diplomados na preparação para a vida profissional foram o alargamento da rede de contactos profissionais $(30 \%)$, a progressão na carreira $(34,8 \%)$ e o desenvolvimento de capacidades para a exploração de novas oportunidades de emprego (36,1\%). Como se referiu atrás, os parâmetros do modelo DOTS, mais vocacionado para compreender as carreiras profissionais, designadamente a perceção da oportunidade de novo trabalho e a aprendizagem da transição de trabalho - de ser capaz de transferir e direcionar oportunidades -, correspondem de facto aos elementos menos valorizados pelos nossos estudantes (Boffo, 2019).

\section{Contributos dos cursos para o desenvolvimento pessoal, profissional e social}

A maioria dos inquiridos afirmou que a licenciatura contribuiu para se sentir melhor consigo mesmo e sentir-se mais capaz, bem como tornar-

Gráfico $4 \triangleright$ Preparação da licenciatura para a vida profissional

Desenvolveu capacidade crítica, de planeamento e inovação no trabalho

Alargou rede de contactos profissionais

Aumentou a capacidade de uso das tecnologias na pática laboral

Permitiu a progressão na carreira

Desenvolvimento de capacidades de interagir e resolver problemas

Métodos de trabalho profissionais

Desenvolver capacidades para a exploração de oportunidades de emprego
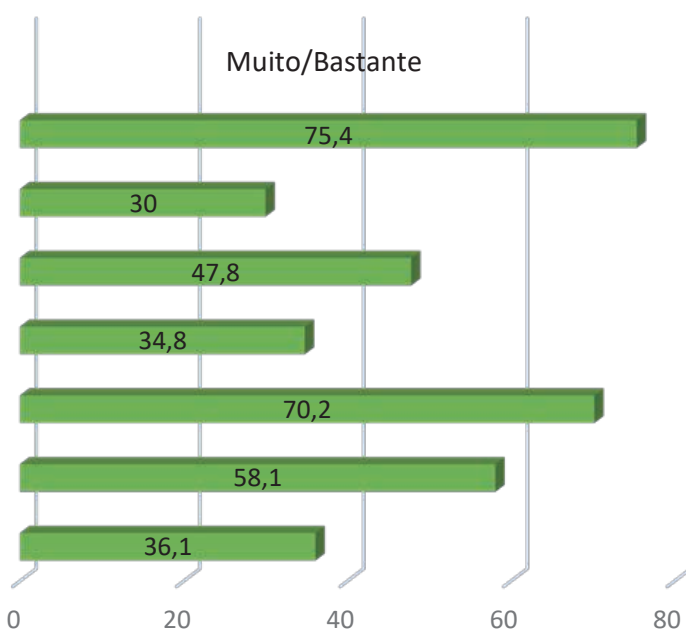

Fonte: Elaboração própria (Abrantes et al., 2018, p. 23) 
-se um cidadão mais ativo e participativo. Trata-se de contributos dos cursos para as dimensões do desenvolvimento pessoal, profissional e social. O contributo da frequência do curso da UAb para o alargamento das redes, independentemente da sua natureza (pessoal, social ou profissional), não foi, de novo, muito expressivo. Estes resultados parecem confirmar o que referem Hartmann \& Komljenovic (2020), associando os dispositivos de empregabilidade à articulação entre as instituições de ensino superior e o seu contexto, a comunidade envolvente e global. Muito para além do mercado de trabalho, portanto.

\section{Perceções sobre a imagem pública da UAb e as características dos seus estudantes}

O relativo desconhecimento público acerca da Universidade Aberta enquanto única universidade pública de ensino a distância em Portugal é algo com que muitos dos seus estudantes, docentes e funcionários se confrontam com frequência. Neste sentido, os diplomados, quando questionados sobre as perceções que os contactos profissionais (empregadores e outros) têm sobre a licenciatura realizada na UAb, revelaram que estas ainda não são tão positivas quanto desejado. Importa destacar que $33,6 \%$ referem que a licenciatura da Universidade Aberta é desvalorizada face a outras licenciaturas da mesma área científica e profissional e que apenas $17,6 \%$ que consideraram o curso que concluíram como bastante valorizado. Os restantes $33,6 \%$ indicaram que a licenciatura é igualmente valorizada.

A par da imagem pública da UAb, pretendeu-se perceber a auto-imagem dos licenciados desta universidade. Para tal, foi solicitado aos inquiridos que indicassem três características associadas a um licenciado da Universidade Aberta. Salientamos algumas das características que foram mais referidas, associadas àquilo que os inquiridos consideram ser o resultado da experiência de um estudante da UAb: perseverante, empenhado, colaborativo, automotivado, organizado, competente.

Tratando-se de uma questão aberta, as respostas foram analisadas quanto ao seu conteúdo e agrupadas em três grandes categorias que emergiram das próprias respostas e que remetem para competências de natureza diferente. A saber, competências pessoais, competências sociais e competências técnicas.

- A primeira categoria remete para competências de ordem pessoal e aqui encontramos referências: ao carácter ambicioso, à necessidade de enriquecimento pessoal, de autorrealização e de desenvolvimento; à autodisciplina e à (auto)confiança; à (automotivação e entusiasmo; à competência (equivalente à de outros estudantes, de outras universidades), às capacidades (de

Gráfico $5 \triangleright$ Contributos do curso para o desenvolvimento pessoal, profissional e social

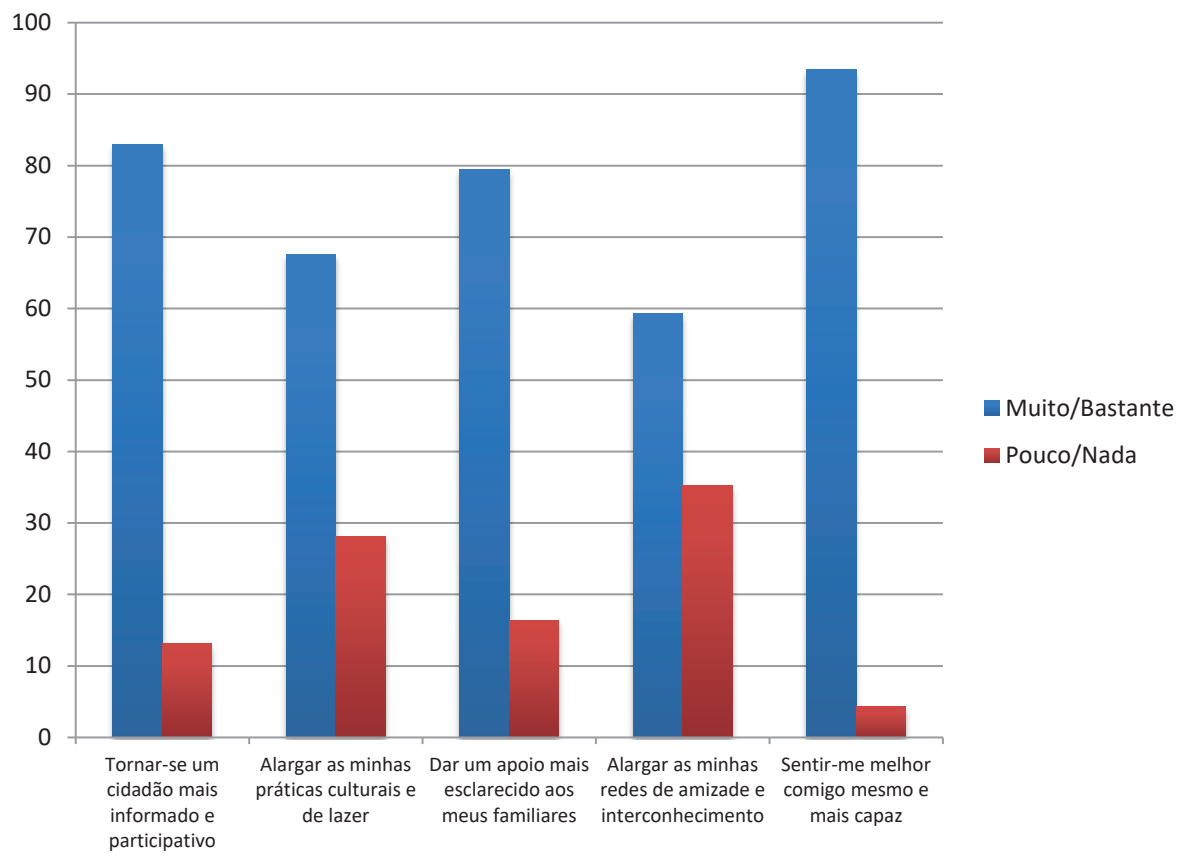

Fonte: Elaboração própria (Abrantes et al., 2018, p. 24) 
Gráfico $6 \triangleright$ Imagem pública da Universidade Aberta

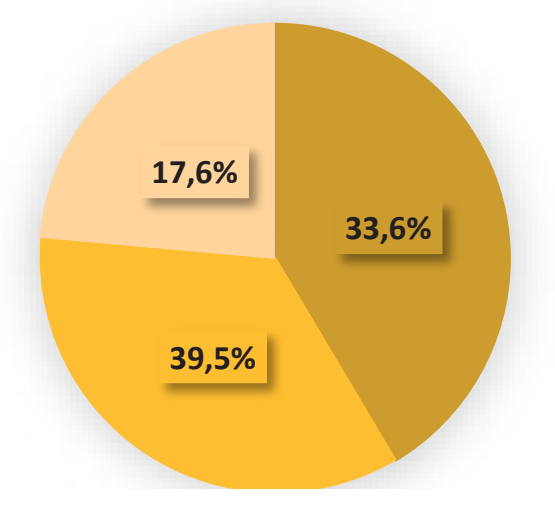

\author{
Desvalorizada (face a outras \\ da mesma área) \\ - Tão valorizada como outras \\ da mesma área \\ Bastante valorizada
}

Fonte: Elaboração própria (Abrantes et al., 2018, p. 24)

aprender, de estudo, de intervenção, de superação, de trabalho); à comunicação e desinibição; à dedicação, empenho, aplicação, disponibilidade, interesse, responsabilidade; à determinação, esforço, força de vontade, luta, persistência, perseverança, resiliência; à gratidão, otimismo, felicidade, humildade, prestígio, respeito.

- A segunda categoria engloba competências de natureza social, designadamente: cidadania, espírito crítico, preparação, esclarecimento, consciência, participação, reflexão; destaque para a comodidade; flexibilidade; gestão do tempo (horários); liberdade; com maior maturidade e experiência; estudante-trabalhador, com pouca disponibilidade, com necessidade de valências para a carreira e de qualificação; oportunidade, acessibilidade, redução de custos, cosmopolita; prestação de um apoio esclarecido à família.

- Finalmente, as competências de ordem técnica, que remetem para aspetos mais diretamente relacionados com os domínios do trabalho. Foram aqui referidas as seguintes características: conhecimento (construtor do seu próprio conhecimento), autonomia, (auto)didata, informação, cultura, inteligência, curiosidade; domínio das tecnologias, inovação, criatividade; interatividade; colaboração, amizade, altruísmo, solidariedade; eficiência, eficácia, exigência, melhoria contínua, rigor; método, organização, objetividade, analítico; dinâmico, prático, pró-atividade, empreendedorismo; coragem (por optar por um ensino não tradicional), diferença, audácia.

Embora tenham sido residuais as referências a características pela negativa, importa também dar conta delas nesta análise. Assim, os aspetos menos positivos destacados pelos licenciados inquiridos foram o facto de se sentirem desvalorizados (por terceiros), o que se relaciona com alguma falta de reconhecimento público dos cursos que ainda persiste e com falta de apoio no emprego.

\section{Conclusões: os impactos reais de aprender a distância}

As respostas dos estudantes confirmam que a oferta educativa da Universidade Aberta está orientada para estudantes adultos, trabalhadores a tempo inteiro, com intervalos mais ou menos longos até ao ensino superior, espalhados por todo o território nacional e inclusive noutros países, a maioria dos quais não teria possibilidades de frequentar o ensino superior em outra modalidade (Abrantes et al., 2018; Abrantes et al., 2016a; Abrantes et al., 2016b; Abrantes et al., 2016c; Magano et al., 2016; Magano et al., 2018; Neves et al., 2017).

Os estudantes estão satisfeitos com a realização da sua licenciatura online na instituição, na medida em que revelam conforto no uso da plataforma e reconhecem vantagens do regime de aprendizagem. Neste cenário, procuram o curso para ampliar a sua autonomia, cultura geral e sentido crítico. Também para o seu desenvolvimento pessoal, social e profissional, afirmando que se sentiram mais capazes e melhores enquanto cidadãos, mais ativos e participativos. A motivação e a satisfação para a frequência do curso revelam a importância que a obtenção de um diploma do ensino superior ainda representa quer pelo que se refere a prestígio social associado, quer também pela possibilidade de mudança profissional e mobilidade social (Bourdieu, 1979). Uma proporção significativa de diplomados da UAb respondentes registou impactos positivos na sua carreira laboral, ainda que seja também de 
assinalar o número expressivo de licenciados para quem a progressão laboral não é o principal objetivo a atingir, o que varia também em função da idade.

A pesquisa sobre o fenómeno da empregabilidade no ensino superior precisa de mais desenvolvimento. Os estudantes adultos apresentam um conjunto de necessidades diferenciadas, mais relacionadas com a adquisição de competências para melhorar a sua empregabilidade e com o desenvolvimento das suas carreiras, na medida em que já se encontram inseridos no mercado de trabalho. Este estudo assume-se como um contributo para esta problemática.

Em síntese, os diplomados da UAb valorizam a experiência de desenvolverem a sua aprendizagem em ambiente online. Destacam o facto de adquirirem e desenvolverem competências para o trabalho, mas também o contributo para o seu desenvolvimento enquanto indivíduos, para a sua qualidade de vida. Os dados mostram ainda que os estudantes licenciados da Universidade Aberta reconhecem os meios digitais como uma forma de capacitação pessoal que lhes permite não apenas aproveitar as oportunidades educacionais e formativas de forma mais flexível e adaptável às condições de vida de cada um, como também desenvolver um conjunto de competências tecnológicas nas quais se inserem as competências de comunicação, interação, trabalho colaborativo, etc., consideradas fundamentais nos atuais contextos de empregabilidade (OCDE, 2005, 2018). Recuperamos, assim, a ideia de educação ao longo da vida associada ao ensino a distância como importante forma de desenvolvimento e aquisição não só de conhecimentos como também de competências transversais fundamentais a todos os contextos da vida e à mobilidade profissional.

Estas conclusões são motivadoras para o aprofundamento e desenvolvimento deste estudo em algumas das suas dimensões. Referimo-nos primeiramente ao alargamento da dimensão metodológica de modo que integre outros atores-chave deste processo, como os empregadores, no sentido de se recolherem dados sobre as suas perceções relativamente à formação a distância dos seus funcionários. Além disso, seria interessante procurar explorar evidências dos questionários com entrevistas aos diplomados, permitindo aprofundar questões sobre o seu percurso na UAb, as experiências vividas e os impactos destas experiências formativas na sua vida pessoal, social e profissional. Finalmente, a incorporação de dados sobre os diplomados dos estudantes do $2 .^{\circ}$ e $3 .^{\circ}$ ciclos, adequando as questões às especificidades pedagógicas que o modelo da UAb preconiza para estes ciclos de estudo. Este aspeto é particularmente relevante, dada a atual tendência de cada vez mais trabalhadores terem o perfil formativo que Harvey (2005) define como transformative.

\section{Referências bibliográficas}

Abrantes, P. (Coord.), Bäckström, B., Falé, I., Henriques, S., Jacquinet, M., Magano, O., Neves, C. Ramos, M. R., \& Silva, A. P. (2018). Percursos profissionais e de vida dos licenciados da UAb (2. a ed.). Observatório dos Percursos Profissionais e de Vida dos Diplomados da Universidade Aberta. Lisboa: Universidade Aberta. Retirado de http:// hdl.handle.net/10400.2/7859

Abrantes, P., Henriques, S., Bäckström, B., Jacquinet, M., Magano, O., \& Neves, A. C. (2016a). Fazer a licenciatura a distância: Percursos e impactos. In C. A. Gomes, M. Figueiredo, A. Ramalho \& R. Rocha (Eds.), Atas XIII Congresso SPCE: Fronteiras, diálogos e transições na educação (pp. 1601-1610). Viseu: Escola Superior de Educação do Instituto Politécnico de Viseu. Retirado de http://www.esev. ipv.pt/spce16/atas/XIII_SPCE_2016_atas_D.pdf

Abrantes, P. (Coord.), Bäckström, B., Neves, C., Jacquinet, M., Magano, O., \& Henriques, S. (2016b). Resultados do questionário aos percursos laborais e de vida dos licenciados da UAb: Relatório síntese. Lisboa: Universidade Aberta. Retirado de http:// hdl.handle.net/10400.2/4997

Abrantes, P., Henriques, S., Bäckström, B., Jacquinet, M., Magano, M., Neves, C. (2016c), Fazer a licenciatura a distância: Percursos e impactos. Comunicação apresentada no XIII Congresso da SPCE - Sociedade Portuguesa de Ciências da Educação: Fronteiras, Diálogos e Transições. Instituto Politécnico de Viseu, Viseu.

Aires, L., Azevedo, J., Gaspar, I., \& Teixeira, A. (2007). Comunidades virtuais de aprendizagem e identidades no ensino superior. Porto: Universidade Aberta e Fundação para a Ciência e a Tecnologia.

Boffo, V. (2019). Employability and Higher Education: A category for the future. New Directions for Adult \& Continuing Education, (163), 11-23. doi: 10.1002/ace.20338

Bourdieu, P. (1979). La distinction: Critique sociale du jugement. Paris: Les Éditions de Minuit.

Brown, P., Hesketh, A., \& Williams, S. (2002). Employability in a knowledge-driven economy (Working paper, n.o 26). Cardiff: School of Social Sciences.

Cadin, C., Guerin, F., \& Pigeyre, F. (1997). Gestion des ressources humaines. Pratique et éléments de théorie. Paris: Dunod.

Charlot, B., \& Glasman, D. (1998). Introduction. In B Charlot \& D. Glasman (Eds.), Les jeunes, I'insertion, I'emploi (pp. 11-26). Paris: PUF.

Deem, R. (1998). "New managerialism" and higher education: The management of performances and cultures in universities in the United Kingdom. International Studies in Sociology of Education, 8(1), 47-70. doi:10.1080/0962021980020014

Finch, D. F., Hamilton, L. K., Riley, B., \& Zehner, M. (2013). An exploratory study of factors affecting undergraduate employability. Education+Training, 55(7), 681-704. doi:10.1108/ET-07-2012-0077 
Hartmann, E., \& Komljenovic, J. (2020). The employability dispositif, or the re-articulation of the relationship between universities and their environment. Journal of Education Policy. doi: 10.1080/02680939.2020.1725983

Harvey, L. (2005). A history and critique of quality evaluation in the UK. Quality Assurance in Education, 13(4), 263-276.

Knight, T. P., \& Yorke, M. (2003). Assessment learning and employability. Inglaterra: SRHE and Open University Press Imprint.

Magano, O., Abrantes, P., Bäckström, B., Neves, C., Jacquinet, M., \& Henriques, S. (2016). Mobilidade social dos diplomados da Universidade Aberta: Percursos de vida e de trabalho. Portugal - Território de Territórios. Atas do IX Congresso Português de Sociologia. Lisboa: Associação Portuguesa de Sociologia. Retirado de http://www.aps.pt/ ix_congresso/docs/final/COM0286.pdf

Magano, O., Abrantes, P., Ramos, M. R., Bäckström, B., Neves, C., Henriques, S., Jacquinet, M., Falé, I., \& Silva, A. P. (2018). O contributo do ensino a distância online para a mobilidade académica e social: O caso dos diplomados da Universidade Aberta. Comunicação apresentada no XIV Congresso SPCE 2018. Universidade de Coimbra, Coimbra.

McQuaid, R. W., \& Lindsay, C. (2005). The concept of employability. Urban Studies, 42(2), 197-219.

Mendes, A. Q., Bastos, G., Amante, L., Aires, L., \& Cardoso, T. (2018). Modelo pedagógico virtual: Cenários de desenvolvimento. Lisboa: UAb

Neves, C., Henriques, S., Abrantes, P., Bäckström, B., Jacquinet, M., \& Magano, O. (2017). Licenciados da Universidade Aberta: Percursos, motivações e aprendizagens em ambiente digital. Investigar em Educação - Revista da Sociedade Portuguesa de Ciências da Educação, II(6), 175-197.

OCDE - Organização para a Cooperação e Desenvolvimento Económico. (2005). The definition and selection of key competencies. França: OCDE.

OCDE - Organização para a Cooperação e Desenvolvimento Económico. (2018). The future of education and skills - Education 2030. França: OCDE.

Pereira, A., Mendes, Q. A., Morgado, L., Amante, L., \& Bidarra, J. (2007). Modelo pedagógico virtual da Universidade Aberta. Lisboa: Universidade Aberta.

Pereira, C. D. (2007). Nova educação na nova ciência para a nova sociedade. Porto: Universidade do Porto.

Pool, L. D., \& Sewell, P. (2007). The key to employability: Developing a practical model of graduate employability. Education + Training 49, 277-289. doi:10.1108/00400910710754435

Silva, A. P. (2010). As competências para a empregabilidade no ensino superior (Dissertação de mestrado). Universidade de Aveiro - Secção Autónoma de Ciências Sociais, Jurídicas e Políticas, Aveiro.

Silva, A. P., Lourtie, P., \& Aires, L. (2013). Employability in online higher education: A case study. Retirado de http://www.irrodl.org/index.php/irrodl/article/ view/1262/2426

Yorke, M. (2006). Employability in Higher Education: What It Is-What It Is Not: Learning \& Employability Series 1. The Higher Education Academy, York.

Zulauf, M. (2006). Ensino superior e desenvolvimento de habilidades para a empregabilidade: Explorando a visão dos estudantes. Sociologias, 16, 126-155.

Esta obra está licenciada com uma Licença Creative Commons Atribuição - 4.0 (CC BY 4.0).

Recebido a 22/04/2020. Aceite para publicação a 28/07/2020.

Susana Henriques. Centro de Investigação e Estudos de Sociologia (CIES-Iscte), Iscte - Instituto Universitário de Lisboa \& Universidade Aberta (UAb), Portugal. Email: Susana.Henriques@uab.pt

Cláudia Neves. Laboratório de Educação e Ensino a Distância (LE@D), Universidade Aberta (UAb), Portugal. Email: Claudia.Neves@uab.pt

Ana Paula Silva. Universidade Aberta (UAb), Portugal. Email: AnaP.Silva@uab.pt

Pedro Abrantes. Centro de Investigação e Estudos de Sociologia (CIES-Iscte), Iscte - Instituto Universitário de Lisboa \& Universidade Aberta (UAb), Portugal. Email: Pedro.Abrantes@uab.pt

Bárbara Bäckström. Universidade Aberta (UAb); CICS.NOVA \& Centro de Estudos das Migrações e Relações Interculturais (CEMRI), Portugal. Email: Barbara.Backstrom@uab.pt

Isabel Falé. Centro de Linguística da Universidade de Lisboa (CLUL), Universidade Aberta, Portugal. Email: Isabel.Fale@uab.pt

Marc Jacquinet. Universidade Aberta (UAb) \& Centro de Investigação sobre o Espaço e as Organizações (CIEO), Universidade Algarve, Portugal. Email: Marc.Jacquinet@uab.pt

Olga Magano. Centro de Investigação e Estudos de Sociologia (CIES-Iscte), Iscte - Instituto Universitário de Lisboa \& Universidade Aberta (UAb), Portugal. Email: Olga.Magano@uab.pt

Maria do Rosário Ramos. Universidade Aberta (UAb) \& Centro de Matemática, Aplicações Fundamentais e Investigação Operacional (CMAFcIO, UL), Portugal. Email: MariaR.Ramos@uab.pt 